\title{
Del pictograma a la imagen: herramientas de comunicación y lenguaje en personas con síndrome de Asperger a través de recursos visuales para la inclusión social
}

\author{
Pedro José Regis Sansalonis ${ }^{1}$ \\ Departamento de Didáctica de la Expresión Musical, Plástica y Corporal. \\ pregis@ujaen.es \\ María Dolores CALlejón ChInchilla ${ }^{2}$ \\ Departamento de Didáctica de la Expresión Musical, Plástica y Corporal. \\ callejon@ujaen.es
}

Recibido: 17-3-15

Aprobado: 13-11-15

\section{Resumen}

Se presenta en este texto, una introducción al Síndrome de Asperger y aquellas características que lo distinguen, con el fin de conocer un poco más, en qué consiste este Trastorno Generalizado del Desarrollo (TGD). Además, se pretende facilitar cuales son las herramientas de comunicación y lenguaje más aptas para la enseñanza y aprendizaje del sujeto, haciendo hincapié en los recursos visuales, audiovisuales y artísticos como herramientas de aprendizaje para su inclusión social en cualquier ámbito de la sociedad (colegios, institutos, asociaciones, universidades o administraciones).

Palabras clave: Síndrome de Asperger; inclusión social; herramientas de comunicación y lenguaje; habilidades sociales y habilidades comunicativas.

From pictogramme to image

\begin{abstract}
It appears in this text, an introduction to Asperger's Syndrome and those characteristics that distinguish it, in order to know a bit more, of what there consists this Pervasive Developmental Disorder (PDD). In addition, it is tried to facilitate which are the most suitable tools of communication and language for the education and learning of the subject, emphasizing in the visual, audio-visual and artistic resources as tools of learning for his social incorporation in some area of the company (colleges, institutes, associations, universities or administrations). Key words: Asperger's Syndrome; Social Incorporation; Tools of Communication and Language; Social skills and Communicative skills.
\end{abstract}




\section{Introducción al Síndrome de Asperger}

“Todos somos genios. Pero si juzgas a un pez por su habilidad de trepar árboles, vivirá toda su vida pensando que es un inútil”.

(Albert Einstein.

Tuvo Síndrome de Asperger)

El Síndrome de Asperger no es una enfermedad, por lo tanto no tiene cura. Es un TGD (Trastorno Generalizado del Desarrollo) y se encuentra dentro del TEA (Trastorno del Espectro Autista), junto con otros trastornos, como define la Asociación de Psicología Americana ${ }^{3}$ en el manual DSM-V.

Uno de los autores actuales que más ha profundizado sobre el Síndrome de Asperger es Tony Attwood, en su libro "Guía del Síndrome de Asperger". Para Attwood (2011, pág. 56), los niños con síndrome de Asperger tienen las siguientes características:

- Retraso de la madurez y el razonamiento social.

- Empatía inmadura.

- Dificultades para hacer amigos, con frecuencia, son objeto de burla de otros niños.

- Dificultades con la comunicación y el control de las emociones.

- Destrezas poco comunes del lenguaje: vocabulario y sintaxis normales pero retraso de la capacidad de conversación, prosodia poco común y tendencia a ser pedantes.

- Fascinación por un tema que es extravagante, en la intensidad o en su forma de prestarle atención.

- Dificultades para mantener la atención en clase.

- Perfil poco común de aptitudes de aprendizaje.

- Necesidad de apoyo en algunas destrezas de autosuficiencia y de organización.

- Torpeza motora tanto por lo que se refiere a la marcha como a la coordinación.

- Sensibilidad a los ruidos, aromas o texturas concretos.

Aunque sí se puede apreciar una notable mejoría en todas aquellas capacidades en las que ellos encuentran dificultades, se deben trabajar en aquellas que tienen que ver con las habilidades sociales, habilidades de aprendizaje en contextos educativos, iniciativa personal, imagen e identidad, habilidades comunicativas o comportamientos repetitivos o estereotipados.

Y no hay mejor utilidad para conseguir avanzar en el desarrollo de sus capacidades, que la utilización de diferentes herramientas visuales para poder expresar sus emociones. Según Attwood (2011: 209) “ (...) aunque puedan tener una capacidad intelectual considerable, sobre todo el en área de conocimientos intelectuales, se muestran confusos e inmaduros con respecto a los sentimientos (...) y a una ausencia de reciprocidad social o emocional (...)".

Ante la necesidad de trabajar con estas personas la utilización de apoyos visuales, con el fin de asimilar ciertos conceptos, actitudes, conductas, etc de su vida diaria, se 
apuesta por la utilización de medios de masas cada vez más utilizados y accesibles en la sociedad, como puede ser una cámara fotográfica, un móvil de última generación, un Ipad, etc, sin olvidar la importancia que les ha supuesto desde niños, la utilización de los pictogramas como herramienta de apoyo visual en su aprendizaje.

La utilización de metodologías cognitivo-conductuales (sin descartar otras que pueden resultar válidas o pueden ocasionar un punto de vista diferente en base a aquellos objetivos que se plantean) son las más idóneas para poder establecer soluciones a las diversas conductas disruptivas que prevalecen en niños y adolescentes con Síndrome de Asperger y que forman parte no sólo en el aspecto social sino también en el ámbito comunicativo.

Acciones tan cotidianas como ir a al lugar de trabajo o estudio, conducir el coche, viajar a través de los distintos medios de transporte, etc, están llenos de símbolos que resultan ser cotidianos por el uso visual frecuente del que se observa.

La utilización de apoyos visuales como medio de utilización y desarrollo de la autonomía personal de adolescentes con Síndrome de Asperger, y que poseen una diversidad comunicativa, social y cognitiva diferente a sus iguales, ayudan a resolver los conflictos cotidianos que pueden surgirles en cualquier actividad que realicen. Aunque es verdad que cada sujeto con asperger es diferente, recurrir a estos medios para una mejora no solo en el ámbito socio-educativo del sujeto además de la calidad de vida, sino también para un mejor conocimiento de todas aquellas personas u organismos que desconocen este Trastorno General del Desarrollo (TGD) (Barrios, 2013; Regis, 2014).

\section{Los Sistemas de Comunicación Alternativa y Comunicativa (SCAA) en Asperger}

Estos sistemas de comunicación y lenguaje, aparecieron en los años sesenta del siglo XX, cuando se requirió la utilización de signos manuales en personas con deficiencia social asociada, sordera y deficiencias múltiples. La capacidad y aptitud de las diferentes personas en cuanto al uso de la comunicación y sus múltiples formas de utilización, vienen determinadas por acciones como por ejemplo, señalar, movimientos de las extremidades, emociones, gestos, etc.

En el caso de España, fue en los años ochenta cuando empezó a conocerse y a utilizarse estos sistemas de comunicación, vigentes en la actualidad. Como concepto, empezaremos a utilizar aquello que propuso Tamarit (1989):

Los Sistemas Alternativos de Comunicación son instrumentos de intervención logopédica/educativa destinados a personas con alteraciones diversas de la comunicación y/o del lenguaje, y cuyo objetivo es la enseñanza mediante procedimientos específicos de instrucción, de un conjunto estructurado de códigos no vocales, necesitados o no de soporte físico, los cuales, mediante esos mismos u otros procedimientos específicos de instrucción, permiten funciones de representación y sirven para llevar a cabo actos de comunicación (funcional, espontánea y generalizable) por sí solos, o en conjunción con códigos vocales, o como apoyo parcial a los mismos o en conjunción con otros códigos no vocales. 
Los objetivos para la utilización de estos sistemas alternativos de comunicación derivan en la posibilidad de las siguientes variables:

- Proporcionar un medio de comunicación alternativo y temporal para un futuro restablecimiento del habla del sujeto.

- Facilitar el desarrollo de la comunicación oral.

- Promover un medio de comunicación cuando el habla del sujeto no llega a ser funcional.

- A continuación, conoceremos algunos de estos sistemas comunicativos alternativos y aumentativos de comunicación en personas con el Trastorno del Espectro Autista (TEA).

- Según Lloyd y Karlan (1984) establecen una clasificación de sistemas de comunicación sin ayuda y con ayuda. En cuanto a los primeros, poseen unas características especiales:

- Signos evocados y producidos de memoria.

- No requieren de una gran capacidad cognoscitiva.

- Poseen un gran dinamismo.

- Ofrecen eficacia y rapidez en la comunicación.

- Disponen de un vocabulario amplio.

- Emisor y receptor deben de reconocer el sistema de comunicación.

- Se requiere de destrezas motoras por parte de los usuarios.

- Se pueden enseñar desde edades muy tempranas.

Existen diversos tipos de sistemas sin ayuda:

\section{- Dactilografía}

Representación del alfabeto a través de diferentes posiciones de las manos.

\section{- Lengua de signos}

Es un lenguaje con su propia estructura gramatical y funciones sintácticas.

\section{- Benson Schaeffer y su programa de Comunicación Total.}

Este programa de Comunicación Total se caracteriza por su utilización en personas con Trastornos Generalizados del Desarrollo y en especial, niños con autismo, conteniendo dos componentes fundamentales o también denominado un sistema bimodal: por un lado, el denominado Habla signado (producción del niño/adulto del habla y de los signos de una manera simultánea) y por otro lado, la denominada Comunicación simultánea (el empleo del acto comunicativo a través del habla y de los signos de personas adultas, niños, mayores...).

En lo que se refiere a los sistemas comunicativos con ayuda, poseen las siguientes características:

- Son estáticos.

- Son fáciles de aprender y ser aplicados.

- Ralentizan la comunicación.

- Emisor y receptor pueden no conocer el soporte.

- Dependen de soportes externos al propio cuerpo.

- Demandan mínimas destrezas motoras. 
En lo que se refiere a su aplicación, se realiza a través de sesiones de aprendizaje de imitación verbal y de signos, pues estas sesiones deben de ser independientes. Cuando se aprende el signo, aprende a diferenciar cuáles signos ha aprendido conjuntamente con las palabras que determinan el significado de esos signos a través de un especialista logopeda.

Tras la repetición de este proceso en el cual, el sujeto relaciona el signo utilizando los vocablos que representan esas palabras, donde después, la relación de aquellos signos con objetos cotidianos y conocidos por el sujeto o los sujetos, además de actividades muy deseadas y conocidas por este, obtienen una respuestas más factible y provocan un desarrollo comunicativo más real y obtenible.

Existen diversos tipos de sistemas con ayuda:

- Signos tangibles

Son objetos que guardan una estrecha relación con otros objetos que representan.

- Signos gráficos

Se utilizan dibujos y/o imágenes que guardan una relación directa con aquello que se hace referencia.

\section{- Los Sistemas Pictográficos de Comunicación (SPC).}

Los Sistemas Pictográficos de Comunicación (SPC) fueron creados en 1981 por Roxana Mayer - Johnson. Alrededor de 5000 pictogramas en blanco y negro, y además en imágenes a todo color, fueron recogidos en un libro en el cual, estaba acompañado por la representación de estas imágenes en diferentes idiomas y aspectos ortográficos.

Según Tuset (2011: 11) esa gran cantidad de imágenes fueron recogidas en ocho categorías: verbos, descripciones, alimentos, ocio, nombres, cosas misceláneas, personas y lo social. Aunque son unas categorías bastantes generales que engloban miles de imágenes, y que es uno de los sistemas pictográficos más utilizados en el mundo gracias a su "alta definición visual" con respecto a las imágenes y a un software denominado $<<$ Boardmaker $>>$ que permite a aquellas personas que lo utilizan crear pictogramas basados a través de mensajes usados por medio del ordenador.

Los sistemas pictográficos de comunicación representan todo tipo de conceptos, acciones (individuales o grupales) $\mathrm{u}$ objetos en forma de dibujos, utilizando un lenguaje visual que se ve reflejado a través de imágenes muy simples para un mejor entendimiento de lo que se expone ante ellos. Su utilización como medio de comunicación y aprendizaje, persigue los siguientes objetivos:

- Aprender la realización de una determinada actividad a través de las diversas conductas que se exponen en los pictogramas.

- Potenciar las habilidades comunicativas con el fin de expresar sus opiniones ante cualquier hecho que se produzca en sus rutinas sociales, educativas, profesionales, etc.

- Comprender todos aquellos aspectos de la vida diaria que les rodea, no sólo objetos, sino también personas (y qué tipo de personas), acciones, sonidos, olores, etc.

- Aprender a expresar sus opiniones, preferencias y deseos. 
- Facilitar una mejor comprensión de los sentimientos y deseos de los demás para un mejor reconocimiento de los motivos de sus acciones.

No obstante, el trabajo que se realiza con ellos en términos de comunicación y lenguaje (comprensión oral, comprensión escrita, expresión oral y expresión escrita), refuerza a su vez, lo social de estas personas.

\section{- El Programa PECS}

Este sistema de comunicación por intercambio de imágenes (Picture Exchange Communication System) está basado en los análisis aplicados de la conducta de B.F. Skinner (1957). Numerosas publicaciones demuestran que las técnicas específicas que se llevan a cabo a través del ABA (Análisis de la Conducta Aplicada) pueden ayudar a sujetos con autismo para que puedan aprender a desarrollar habilidades tan dificultosas para ellos mismos como por ejemplo el comunicarse, jugar con los otros, obtener éxito en el trabajo o simplemente desarrollar relaciones interpersonales.

Estudios demuestran que la utilización de éstas técnicas dentro de programas individualizados con una atención temprana a niños con autismo, y el hecho de que estos programas refuerzan la integridad del sujeto (interviniendo en áreas tan importantes como habilidades sociales, habilidades comunicativas, etc) con el fin de obtener experiencias veraces y positivas en la correcta integridad de los sujetos que practican estas técnicas.

Sin embargo la utilización de estas técnicas, han demostrado la mejora respecto a su nivel comunicativo, cognitivo y social gracias a la participación en este tipo de conductas desde una edad temprana. No obstante, no todos los sujetos reaccionan y obtienen los mismos resultados. conllevando como consecuencia, la realización de mayores estudios intensivos que determinen las causas y consecuencias de la equidad en cuanto a resultados tras la práctica de estas técnicas para la mejora de la conducta de los sujetos con autismo. Los PECS pueden ser utilizados con personas tanto adultas como con niños con diferentes trastornos, siendo realmente apropiado para personas con una comunicación funcional y no funcional.

Es importante saber y conocer que durante el aprendizaje de los sujetos siendo niños, adquiere una gran importancia el aprendizaje de la comunicación a través de la imágenes, ayudándoles hasta la construcción de funciones comunicativas, estructuras gramaticales y relaciones semánticas.

A través de los PECS podemos trabajar áreas críticas en la comunicación, para una utilización de habilidades comprensivas (seguir un horario establecido, aprender a decir $<<$ sí $>>$, seguir instrucciones que tienen una o varias funciones...) y expresivas (pedir ayuda, a prender a decir $<<$ no $>>$, pedir una cosa o un objeto que se desea...).

\section{Construyendo narrativas}

\section{La imagen: el pictograma}

La cotidianeidad de la vida refleja a cualquier hora y/o en cualquier lugar, cantidad de imágenes que pueden resultar llamativas a la vista de la personas que lo contemplan. Desde pequeños, las imágenes forman parte de la vida y adquieren mucha importancia durante el aprendizaje del individuo. 
Cierto es el dicho aquel que decía "una imagen vale más que mil palabras" y en el caso de las personas que tienen un Trastorno Generalizado del Desarrollo, como en éste caso, el Síndrome de Asperger, su importancia lo es aún más.

Los Aspies (palabra cariñosa para referirse a las personas que padecen este Trastorno General del Desarrollo) al igual que los demás niños, les resulta de gran ayuda la utilización de imágenes como apoyo visual para aprender una determinada acción o símbolo que les puede resultar cotidiano o no.

Las imágenes que pueden ayudar a las personas con asperger, representan un acicate en su constante evolución no sólo en el aspecto social de las personas sino también en el ámbito comunicativo ${ }^{4}$.

Desde una perspectiva social, el pictograma es un recurso muy utilizado desde pequeños para la correcta comprensión de la simbología de la imagen que se está observando. Además, les ayuda a comprender mejor las "leyes" que rigen la sociedad y el comportamiento del ser humano pues, es indudable, que la mejor manera como bien afirman los psicólogos, es la utilización de una metodología cognitivo conductual donde les ayude a comprender el significado de la imagen por medio de lo cognitivo, y conductual porque es importante el aprendizaje de los diferentes pasos o pautas para realizar una correcta acción.

Desde una perspectiva comunicativa, les ayuda a entender y expresar sus emociones, a socializar con los demás, a preguntar y a relacionarse tanto con sus iguales como con aquellas personas con las que conviven en el dia a dia (padres y madres, psicólogos, profesorado, hermanos/as, etc).

\section{El cartel}

Como ilustración, actúa como una imagen expositiva en la que transmite un mensaje que debe de ser recibido por el receptor, positivo o negativo o quizás, no sea esa la intención del cartel. Una de sus funciones más claras, es la pretensión de evocar una imaginación en el espectador ante la idea o concepción que determine el concepto visual del producto que se muestra.

Generalmente, un cartel se puede apreciar en un espacio público o privado, solitario o comunitario, siendo además un icono que puede actuar en cualquier ámbito, ya sea político, cultural, social, religioso, etc.

Todo cartel requiere de unas características que lo hacen llamativo: su color, la escritura, la imagen representada. Puede generar multitud de sentimientos y emociones, un ejemplo es la cartelística llevada a cabo durante la Segunda Guerra Mundial por el bando Nazi como elemento propagandístico de su doctrina.

Esa "excitación óptica" en las personas con Síndrome de Asperger, les llama la atención lo cual les induce a buscar información sobre ella, su relación con otros aspectos de la vida o sus vidas, conformando un círculo vicioso en el cual el objeto y sujeto están relacionados entre sí, buscándose el uno al otro.

\section{Una historieta gráfica: el cómic}

El cómic al igual que el séptimo arte, comparten el mismo hito, es decir, la imagen secuenciada. Es verdad que el cómic se sirve de imágenes fijas mientras que el 
cine es una secuenciación de imágenes en movimiento, pero bien es cierto que ambas técnicas artísticas y visuales comparten un mismo fin, el poder narrar algo significativo.

La primera técnica va acompañada de textos inmersos en los denominados "bocadillos" con la intención de dar información al lector sobre aquello que se está narrando mientras que el cine, está compuesto además por el sonido, una característica importante donde el espectador lo percibe como una sensación no sólo emocional sino también expresivo.

El cómic también posee determinados aspectos de la iconografía. Según Gubern (2000), cada elemento del cómic posee un estereotipo o arquetipo que define a determinadas personas o situaciones que se narran en este medio visual.

La representación de cada imagen conocida como viñeta, viene determinada por toda una serie de planos fijos secuenciales en los cuales, toman protagonismo la historia, el espacio, el tiempo y los personajes. Pero no se debe olvidar la trama o historia que se narra.

Un cómic puede resultar un medio muy accesible y eficaz para el aprendizaje de los niños con Síndrome de Asperger. Como se puede apreciar en la figura número uno, una imagen secuenciada de una determinada acción tan cotidiana como poner la mesa, preparar la mochila el día anterior para al día siguiente al colegio o al instituto o lavarse la cara, puede resultarles atractivo si en vez de utilizar un medio como el pictograma, se utilizase el cómic para la realización de estas acciones.

Se busca la innovación y la utilización de otros medios y recursos para ejercer un aprendizaje significativo (y atractivo para ellos mismos) por parte de los niños o adolescentes con Síndrome de Asperger, implicandose ellos mismos a la realización de estas secuencias, formando parte de la visualización y de la acción artística.

\section{La fotografía}

Desde una perspectiva romántica, la fotografía al igual que la pintura, se puede plasmar la realidad subjetiva de cada individuo que desea mostrar. La accesibilidad a este medio visual durante los últimos años ha sido destacada tanto por la oferta así como por la demanda que requiere este producto. Todos podemos artísticas y esos productos pueden ser considerados obras de arte siempre y cuando tengan una intención de serlo por parte del individuo que crea la obra de arte (en este caso, la reproducción visual).

La fotografía permite la captación instantánea de un momento determinado, con importantes derivaciones desde un carácter artístico, social y de percepción. Representa un instante de la vida, que sirve como recuerdo hacia la persona que ha realizado la acción de captar la imagen, siendo además destacado, su uso en diversos ámbitos resultando atractivo desde una perspectiva social, el aporte visual que pueda significar en sí misma.

Según Regis (2014), el poder de la fotografía funciona en un mismo tiempo reproduciendo una realidad, a veces simbólica, que va más allá de ésta y se interpretan unos parámetros ideológicos y visuales y como huella, provocando una capacidad de evocación, pues es su habilidad de funcionar simultáneamente como 
objeto, como imagen icónica y como representación metafórica, es decir, como símbolo.

La fotografía sirve como obra de arte o icono, que conecta un acontecimiento pasado, que hemos vivido, por lo tanto, una experiencia, con el presente. Su forma y contenido están determinados por la persona activa, es decir, el fotógrafo, que crea a su imagen y semejanza, donde determina su implicación además de su intención en el momento que la realiza.

Las fotografías permiten añorar ciertos detalles olvidados del pasado (aunque en muchas ocasiones ocurre todo lo contrario, es decir, sirve como medio de denuncia y también para dar un valor visual y así no cometer los mismos fallos del pasado) descubriendo nuevas verdades sobre lo vivido, nuestra experiencia o aquello que nos rodea y que pueda ser concebido por otra persona, totalmente distinta, una percepción y apreciación visual diferente a su modo de ver.

Registrar cómo se ven ellos, expresar sentimientos o capacitar alguna acción son algunas de las utilidades que pueden desempeñar gracias a la fotografía. Nuestra propia imagen nos implica a realizar una tarea diversa para un mayor funcionamiento expresivo en los ámbitos oral y escrito de las personas afectadas con éste síndrome. Sin embargo, la participación colectiva de todos los miembros y la ayuda del docente para una mejor convivencia determina como consecuencia una mejor relación social y emocional que nos ayudará a continuar con el proceso.

\section{La imagen secuenciada (1): el stop motion}

Esta técnica artística y audiovisual resulta ser un gran atractivo para todas aquellas personas que la llevan a cabo. A través de ella se representa una realidad, armonizando las técnicas tanto de la fotografía como la del vídeo por medio de la utilización no sólo de fotografías, sino también con el montaje gracias al uso de personajes o escenarios que pueden ser reales o ficticios creados por el autor.

Esta simbiosis entre la fotografía y el vídeo, proyecta la creación de narrativas reales o ficticias que son creadas imagen a imagen. Esta herramienta permite el montaje para su visualización utilizando un tiempo establecido por el creador, permitiendo el factor creativo del individuo sin limitaciones, siendo el sonido y el propio montaje dos factores principales para su desarrollo creativo.

El uso de la técnica de stop motion promueve en las personas con Síndrome de Asperger una serie de factores importantes para su desarrollo personal y social:

1. Les ayuda a ser independientes en la toma de decisiones en el acto de crear o narrar algo.

2. Trabajar en grupo o de forma individual.

3. Fomenta el desarrollo y aplicación de las funciones ejecutivas en la acción artística de la herramienta audiovisual.

4. Adquieren habilidades sociales y comunicativas en la participación con sus iguales o el resto de compañeros y/o conocidos.

5. Aportan creatividad y soluciones que pueden ser extrapoladas a sus vidas cotidianas, ayudándoles a resolver conflictos, observar y respetar las opiniones de los demás, etc. 


\section{La imagen secuenciada (2): el cinemagraph}

Los cinemagraphs son imágenes fijas en las que se puede apreciar un elemento en "vivo" aportando una sensación y acción de movimiento. Se trata de una técnica visual, en la que se mezcla una serie de imágenes y videos para crear una única foto en la cual, se podrá observar uno o varios elementos de la fotografía en movimiento.

Desde una perspectiva más artística, es una herramienta que aporta una singularidad no sólo por su creación creativa y artística, sino también por el uso de diversas herramientas de software profesionales en informática aunque actualmente, pueden ser creadas de cualquier dispositivo móvil o smartphone que posea el artista o el sujeto creativo.

Una nueva técnica atractiva y atrayente para todos los públicos, utilizándose como alternativa a la otra herramienta visual del stop motion en la que se hacía referencia en los párrafos anteriores.

\section{El vídeo}

Según Regis (2014) el vídeo debe ser concebido como una herramienta de comunicación, utilizada para la expresión del lenguaje visual, auditivo, moralista... un recurso para determinar qué es lo que queremos difundir, enseñar o aprender a través de este. Es importante conocer el potencial de este medio comunicativo, un instrumento de diálogo entre todas las personas: desde un docente hasta su alumno, la participación de los padres y familiares de estos además de todas aquellas personas que conforman su entorno como pueden ser sus amigos o amigas.

Sabemos que lo que vemos en la reproducción del vídeo es realista, es decir, existe. Recordando aquella frase de "vale más una imagen que mil palabras", conlleva una narrativa que expresa una intención de querer expresar algo, un trasfondo de poder difundir un hecho o acción que nos hemos o han propuesto. Lo que vemos, puede ser significativo para nosotros o para la persona que lo está mirando, podemos revivir o experimentar acciones y hechos pasados o, simplemente, aquellos que están por vivir o que actualmente se están desarrollando en la actualidad.

El trabajo terapéutico del vídeo, consistirá en poder integrar y/o construir aquello que estoy viendo en parte de mi vida, por ello, en consecuencia, se establece una relacionalidad entre el trabajo terapéutico (en este caso, la visión de la serie) y los cambios que se han ido desarrollando a lo largo de la sesión terapéutica (dualidad cognición - emociones).

La utilización del vídeo, se incluye en una narrativa en relación a lo terapéutico, ya que la percepción juega un papel muy importante en el ambiente, es decir, en el mundo que estamos construyendo y que justifica nuestra existencia.

Las posibilidades del video como técnica terapéutica son infinitas, pues posee un enorme potencial para su utilización como terapia artística, ya que su utilidad promueve su uso con el fin de facilitar, enseñar y aprender aquellos medios y actividades artísticas que adquieren un grado de creatividad excepcional, en cualquier persona, promoviendo el bienestar y la salud de toda aquella persona que pone en práctica la utilización de este medio audiovisual como elemento y herramienta terapéutica. 


\section{Las Historias Sociales}

Son explicaciones de forma oral en las que se nutre de apoyos visuales para una mejor explicación de aquello que se quiere argumentar, utilizando por ejemplo, dibujos para una narración instantánea de lo que se quiere explicar.

Son dibujos o imágenes que se hacen de forma inmediata, es decir, en el mismo momento que se está realizando la explicación o acción a llevar a cabo. La utilización de las historias sociales se apoyan en una serie de objetivos a cumplir por el sujeto a través del objeto de estudio:

- En primer lugar, se quiere proporcionar información sobre la situación a realizar, dirigiendo aquellos actos que se quieren cumplir para que el sujeto o los individuos lo aprendan.

- Por consiguiente, hay que explicar cuáles son las consecuencias si se realiza lo contrario o no se hace de una forma correcta y, por último, hay que detallar de una forma sintética o resumida lo que se ha de aprender.

Las historias sociales son una herramienta muy utilizado por psicólogos y familias que están relacionadas con personas que padecen un trastorno generalizado del desarrollo (un alumno, un miembro de su familia, etc).

\section{Conclusiones}

El conocimiento del Síndrome de Asperger por parte de la sociedad sigue siendo una incógnita por muchos sectores, siendo vital importancia darlo a conocer en distintos ámbitos (institutos, colegios, empresas, universidades, medios de comunicación, etc) partiendo desde el trabajo que se está realizando en asociaciones, hasta poder lograr una mejor adaptación de este colectivo en la sociedad actual.

Es importante difundir y dar a conocer los distintos y diversos sistemas de comunicación y lenguaje que son utilizados en este Trastorno Generalizado del Desarrollo (TGD), mostrando cuáles son los más aptos para un mayor fomento del aprendizaje del individuo con asperger desde que son niños, para tener una mejor adaptación a la vida adulta.

Existen además, numerosas herramientas audiovisuales que pueden ser de ayuda para el desarrollo social, emocional y comunicativo del individuo con asperger. afrontar las tareas cotidianas ya sea en el colegio, en la asociación de asperger de una ciudad determinada o en el propio hogar, debe de resultar estimulante el aprendizaje de aquellas actividades cotidianas utilizando estas herramientas artísticas y socioeducativas que han sido comentadas a lo largo del texto.

En conclusión, lo visual siempre es más atractivo que lo teórico cuando se está hablando de aprendizaje y enseñanza, por ello, no hay que dejarse engañar por las apariencias y menos, por las capacidades que expresan estos individuos, como bien decía Brassai": "Hay muchas fotografías que están llenas de vida pero son confusas y difíciles de recordar. Es la fuerza de una imagen lo que importa".

\section{Referencias bibliográficas}

AMERICAN PSYCHIATRIC ASSOCIATION (APA). (2002). Manual Diagnóstico

y Estadístico de los Trastornos Mentales DSM-IV-TR. Barcelona: Masson. 
AMERICAN PSYCHIATRIC ASSOCIATION (APA). (2014). Manual Diagnóstico y Estadístico de los Trastornos Mentales DSM-V-TR. Barcelona: Masson. ATTWOOD, T. (2011). Guía del Síndrome de Asperger. Barcelona: Paidós. BARRIOS, S. (2013). "Ayúdame a comprender el mundo. Apoyos visuales para la promoción de la autonomía en personas con trastorno del espectro del autismo y trastornos específicos del lenguaje”. En TOG, vol. 10, 8, pp. 92 - 104. A Coruña. http://www.revistatog.com/suple/num8/autismo.pdf (Consultado el 28/01/2015)

GUBERN, R. (2014). Historia del Cine. Barcelona: Anagrama.

LLOYD, L. y Karlan, G. (1984). "Non-speech communication symbols and system: Where have we been and Where are we going?". En Journal of Mental Deficiency Research, 28, pp. 3 - 20. https://www. collaborate.education.purdue.edu/edst/ lloyd/Docs/Articles\%20and\%20Chapters-Lloyd.pdf (Consultado el 15/01/2015)

REGIS, P.J. (2014). "La Fototerapia y Videoterapia como Proyecto de Intervención socio-educativa en adolescentes con Síndrome de Asperger". En Arte y Movimiento, 11, Universidad de Jaén (pendiente de publicación).

SKINNER, B. F. (1957). Verbal behaviour. New York: Appleton Century Crofts.

TAMARIT, J. (1989): "Uso y abuso de los Sistemas Alternativos de Comunicación". En Comunicación, Lenguaje y Educación, 1, pp. 81-94. España. http://www. dialnet.unirioja.es/descarga/articulo/126151.pdf (Consultado el 02/02/2015)

TUSET, P. (2011). Messenger Visual, a pictogram-based Instant Messaging service for individuals with cognitive disability. Proyecto fin de carrera. Universitat Politécnica de Catalunya.

\section{Notas al pie}

1. Licenciado en Historia del Arte. Profesor interino de Ciencias Sociales (Geografía e Historia) por la Junta de Andalucía y doctorando en el Departamento de Didáctica de la Expresión Musical, Plástica y Corporal de la Universidad de Jaén.

2. Doctora en Bellas Artes, Arteterapeuta y Profesora contratada doctora en el Departamento de Didáctica de la Expresión Musical, Plástica y Corporal de la Universidad de Jaén.

3. Las diferencias existentes entre el DSM IV y el DSM V son notables. El Manual de Diagnóstico de Trastornos Mentales (DSM-IV) publicado en 2002 por la Asociación Americana de Psicología, expuso que el denominado Síndrome de Asperger se encontraba dentro de los Trastornos Generalizados del Desarrollo (TGD) junto a otros trastornos como el Sindrome de Rett, Autismo de Alto Funcionamiento, Autismo, Trastorno del Espectro Autista (TEA), etc. Ante la dificultad de "definir" o "establecer" un diagnóstico válido para estas personas que lo padecen. Aún así, y tras la publicación del manual DSM-V (2014), esto ha cambiado. Sindrome de Asperger y los otros trastornos que hemos mencionado anteriormente, se encuentran incluidos en el Trastorno del Espectro Autista (TEA), como concepto global para una mejor definición de estos trastornos.

4. La importancia del pictograma durante los primeros años de vida de los niños y niñas con Sindrome de Asperger es una forma de representación excepcional. En ella, se aprecia el inicio de una acción que se produce, es decir, desde una imagen se va avanzando a través de otras imágenes la realización de una acción determinada que además, va acompañada de un 
texto claro y conciso para la correcta realización de ella. No solamente debe de ser llevado a cabo en su domicilio particular de los sujetos sino también desde el ámbito educativo se debe reforzar buenas conductas para una mejor socialización y comunicación de los individuos con los demás.

5. De nacionalidad húngara, este fotógrafo y profesor de literatura, desarrolló la mayor parte de su vida académica en París siendo uno de los fotógrafos de Hungría mejor conocidos. 